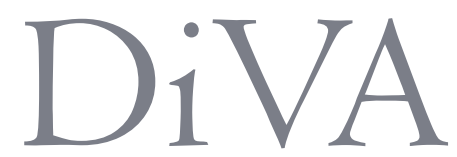

http://uu.diva-portal.org

This is an author produced version of a paper presented the XXth International Conference on Electrical Machines (ICEM), 2-5 Sept, 2012, Marseille, FRANCE. This paper has been peer-reviewed but may not include the final publisher proof-corrections or pagination.

Citation for the published paper:

Eriksson, Sandra; Bernhoff, Hans

"Rotor design for PM generators reflecting the unstable neodymium price" In: Electrical Machines (ICEM), 2012 XXth International Conference on 2012, pp. 1419-1423

ISBN: 978-1-4673-0143-5; 978-1-4673-0141-1

URL: http://dx.doi.org/10.1109/ICEIMach.2012.6350064

Access to the published version may require subscription.

(C) 2011 IEEE. Personal use of this material is permitted. Permission from IEEE must be obtained for all other users, including reprinting/ republishing this material for advertising or promotional purposes, creating new collective works for resale or redistribution to servers or lists, or reuse of any copyrighted components of this work in other works. 


\title{
Rotor Design for PM Generators Reflecting the Unstable Neodymium Price
}

\author{
Sandra Eriksson, Hans Bernhoff
}

\begin{abstract}
The price of rare earth metals such as neodymium is very unstable and has in recent years increased more than $1000 \%$. This leaves the wind power business that uses permanent magnet generators with large insecurity. In this paper, a generator design with an interchangeable rotor is presented, which gives the option of having a rotor with different material depending on the current neodymium price. Thereby, the wind turbine has the same properties with only the generator rotor changing. The suggested alternative, a ferrite rotor, is much heavier than a neodymium rotor. The heavy ferrite rotor indicates an advantage for the vertical axis wind turbine technology with the generator placed on ground level, where the weight is not as important as in the hub. Two similar generator designs are presented, magnet material differences are discussed and the neodymium price limit for when the ferrite rotor is to be preferred is calculated.
\end{abstract}

Index Terms-- Permanent magnet machines, Generators, Wind energy, Neodymium, Ferrites, Costs, Simulation, Rare earth metals.

\section{INTRODUCTION}

$\mathrm{T}$ HE use of permanent magnets for wind turbine generators has increased substantially during the last years. Several of the large wind turbine manufacturers have introduced new products, based on permanent magnet (PM) technology. Most, if not all, of these designs have the PMs made of Neodymium-Iron-Boron, $\mathrm{Nd}_{2} \mathrm{Fe}_{14} \mathrm{~B}$ (abbreviated to $\mathrm{NdFeB}$ ). These magnets include two rare earth metals which have varied much in price lately, neodymium $(\mathrm{Nd})$ and dysprosium (Dy). The price for $\mathrm{Nd}$ increased more than $1000 \%$ from August 2009 to August 2011. The large price fluctuations force us to look for alternative PM materials.

China controls $97 \%$ of the world's rare earth elements. The supply from China is expected to equal China's demand for rare earth metals already in 2012, according to a report from 2010 [1]. The report consists of an in-depth analyze of the current situation concerning rare-earth elements. For $\mathrm{NdFeB} \mathrm{PM}$ generators, the price for Nd will have a large influence on the production cost for the whole wind turbine. The price of other metals, such as copper, is also fluctuating but not in these orders of magnitude. The material availability and price development of $\mathrm{Nd}$ has also been discussed in [2].

In this paper, a wind turbine design is presented with an interchangeable rotor design, eliminating the dependence on the unstable neodymium price. Two suggested generators are presented with the same stator but interchangeable rotors

The Swedish Research Council are acknowledged for contributions to grant number 2010-3950. The Swedish Energy Agency, Vinnova and Statkraft are acknowledged for supporting the Swedish Centre for Renewable Electric Energy Conversion. This work was conducted within the STandUp for ENERGY strategic research framework.

S. Eriksson and H. Bernhoff are with Swedish Centre for Renewable Electric Energy Conversion, Division for Electricity, Department of Engineering Sciences, Uppsala University, Box 534, 75121 Uppsala, Sweden. (e-mail: sandra.eriksson@angstrom.uu.se,

hans.bernhoff@angstrom.uu.se). with different PM material. A ferrite rotor can substitute the $\mathrm{NdFeB}$ rotor at times when the $\mathrm{Nd}$ price is unreasonably high, without altering the wind turbine design.

The $\mathrm{NdFeB}$ magnets are preferably surface mounted and ferrites preferably buried between pole shoes [3]. This is due to the remanence of these two materials. The remanence of $\mathrm{NdFeB}$ is high so no reinforcement of the flux density is needed. For the ferrite magnet the field needs to be reinforced, which is effectively done through pole shoes. These two different options will be studied in this paper; surface mounted $\mathrm{NdFeB}$ PMs and ferrite PMs buried in between pole shoes.

The presented generators are designed to be used together with a vertical axis wind turbine with the generator at ground level [4]-[5]. Therefore, the generator design is not as weight sensitive as for a horizontal axis wind turbine where focus is placed on designing a generator with low weight in order to reduce the hub weight. For a horizontal axis wind turbine, ferrites are a less attractive option since it increases the generator weight substantially. In 2000, ABB presented an innovative wind turbine PM generator design, called Windformer, which had ferrites mounted between pole shoes and was designed for horizontal axis wind turbines [6]. Other applications for ferrite magnets have also been suggested [7].

The two generators presented here are rated at $225 \mathrm{~kW}$. The NdFeB generator has been built, tested and installed in a vertical axis wind turbine [8]. The design method has been verified with experiments on several generators [8]-[9]. The use of PM generators for wind turbines have been studied by several research groups in the past [9]-[11]. Several different configurations have been suggested [12-15]. The main advantage of PMs over electromagnets is that there is no need to electrify the rotor, which practically eliminates rotor losses.

\section{MAGNETIC MATERIALS}

\section{A. Material Properties}

Properties for three magnet grades of three different permanent magnet materials are summarized in Table I.

TABLE I

COMPARISON OF PM MATERIAL

$\begin{array}{llll}\text { Magnet material } & \text { NdFeB } & \text { SmCo } & \text { Ferrite } \\ \text { Grade } & \text { N40H } & 30 \mathrm{U} & \text { Y30 } \\ \text { Remanence, min (T) } & 1.29 & 1.08 & 0.38 \\ \begin{array}{l}\text { Normal coercivity, } \\ \text { min }(\mathrm{kA} / \mathrm{m})\end{array} & 915 & 796 & 240 \\ \begin{array}{l}\text { Intrinsic coercivity, } \\ \text { min }(\mathrm{kA} / \mathrm{m})\end{array} & 1353 & 1990 & 245 \\ \begin{array}{l}\text { Density } \\ \text { PM price (EUR/kg) }\end{array} & 7700 & 8400 & 4700 \\ \begin{array}{l}\text { Material strength } \\ \text { Corrosion protection }\end{array} & \begin{array}{l}\text { Ok } \\ \text { Bad, needs } \\ \text { protective coating }\end{array} & 150^{\mathrm{b}} & 2.17^{\mathrm{a}} \\ & & \text { Very brittle } & \text { Brittle } \\ \end{array}$

Based on invoices from Feb 2012. Prices are based on quotes from manufacturers and reflects PM price for the presented generators and not material price.

${ }^{\mathrm{b}} \mathrm{SmCo}$ price is from July 2011. 
$\mathrm{NdFeB}$ magnets have more than three times higher remanence than the ferrite. Magnets made of SamariumCobalt, SmCo, have only slightly lower remanence than $\mathrm{NdFeB}$, so a machine design based on SmCo would be pretty similar to the $\mathrm{NdFeB}$ machine, but require more $\mathrm{PM}$ material. The price for SmCo is from July 2011. NdFeB and ferrites will be further analysed in this paper.

The ferrite magnet has much lower coercivity than the other two magnets, but since ferrite magnets will be placed between pole shoes they will be protected against high $\mathrm{AC}$ field. SmCo is a more brittle material, which can be a challenge when mounting the PMs. The main disadvantage with PMs made of $\mathrm{NdFeB}$, apart from the varying price, is the sensitivity to corrosion, creating a demand for protective coating. This also makes them more sensitive to mechanical impact, since the coating needs to be kept intact.

The generators considered here, will work at a modest temperature with a minimum of rotor losses. The ambient temperature during operation is expected to be between 20 and 40 degrees, with a control system regulating an air heating/cooling system. Therefore, no risk for demagnetization due to temperature changes is expected.

\section{B. Price Development}

$\mathrm{A} \mathrm{NdFeB}$ magnet includes two rare earth metals which are price sensitive, neodymium and dysprosium. In a $\mathrm{NdFeB}$ magnet, $\mathrm{Nd}$ typically represents about $30 \%$ of the weight but $60 \%$ of the cost whilst Dy typically represents only $3 \%$ of the weight but actually $35 \%$ of the cost. The dependency of these two rare earth metals makes the $\mathrm{NdFeB}$ magnet especially market sensitive. Dysprosium is used to achieve a material with higher coercivity by supplementing a small part of the $\mathrm{Nd}$ in $\mathrm{NdFeB}$. In the application considered here, no extreme coercivity is needed, so focus is on the $\mathrm{Nd}$ price development. However, the price development for Dy has been similar to the one for $\mathrm{Nd}$ and the price for both materials has decreased to about half its value the last six months (Aug 2011-Feb 2012) [16]. Another aspect is that the difference in cost for rare earth metals in China and FOB China (export) is large and also varies with time [16].

From August 2009 to February 2011 the raw material price of PrNd (praseodymium and neodymium alloy price, commonly used to predict $\mathrm{Nd}$ price) increased steadily (pretty much linearly) by $350 \%$. Between February 2011 and February 2012 the price for exported $\mathrm{Nd}$ metal has been changing a lot, see Fig. 1 [16]. In February 2012, the price has decreased a bit but it is still high compared to the price in 2009. The price for PMs for generators is mostly dependent on material price but the geometry also has an impact, since large magnets usually are desired for large generators and are

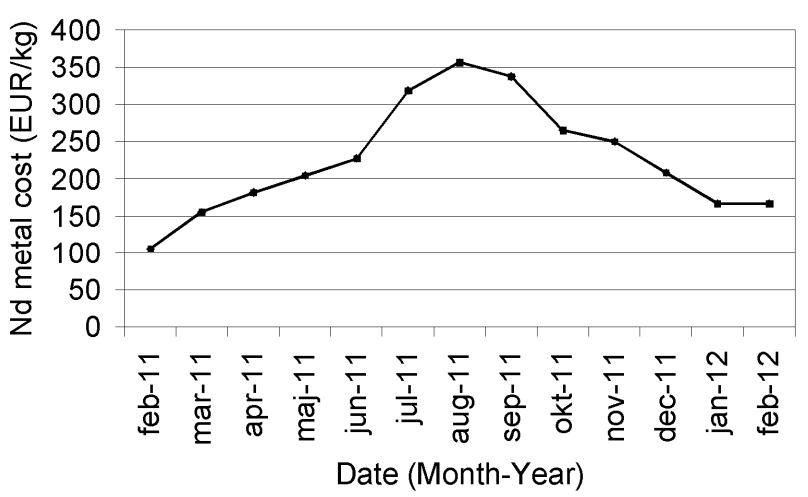

Fig 1. The price development for Nd metal during the last year in EUR/kg (99\% min FOB China) [16]. more expensive to manufacture. Other parameters such as tolerances (both in remanence and dimensions), magnet grade and coating have an impact on the price. The price for the NdFeB PMs for the generator presented here is about 2.4 times higher in February 2012 than it was in July 2010. In July 2010 the price per kilogram for such a large magnet was approximately 29 EUR/kg and in February 2012 it would be about $70 \mathrm{EUR} / \mathrm{kg}$.

The ferrite price is considered to be fairly stable. Therefore, the cost to produce a ferrite generator is easier to predict than the cost for a $\mathrm{NdFeB}$ generator. Depending on how the $\mathrm{Nd}$ price varies, different materials might be preferable as PM material at different times.

\section{ELECTROMAGNETIC MODEL}

The electromagnetic design of the generators is found from simulations using a two-dimensional model solved with the finite element method (FEM). The model is a combined field and circuit model solved through time-stepping. The simulation model has been described more thoroughly and verified with experiments in [8]-[9]. Here, the generator presented in [8] is compared to a newly developed generator with a rotor with ferrites mounted between pole shoes. The generator characteristics were derived by stationary simulations during an iterative design process. This paper focuses on the electromagnetic design but some issues in the mechanical design are also discussed.

\section{GENERATOR DESIGN OBJECTIVES}

The NdFeB generator was designed in 2009 to be used together with a $200 \mathrm{~kW}$ variable speed vertical axis wind turbine with characteristics and design objectives presented in [8] and [17]. The ferrite machine was designed in 2011 with the main design objective to achieve as similar characteristics as the $\mathrm{NdFeB}$ machine as possible.

The special design for the generators is motivated and described in [8]. The $225 \mathrm{~kW}$ generator has to have high overload capability and therefore has quite a lot PMs to achieve the high desired maximum torque. A generator design with a large amount of PMs is of course more sensitive for changes in the PM price. The generator should have a high efficiency for all variable speeds since it is designed for a variable speed turbine.

The generator overload capability is used in two different ways when the wind turbine is operated. First, it is used to control the rotational speed at high power. Second, the generator can be connected to a dump load that will brake the turbine in a few seconds from any operating regime [8]. Thereby an electrical control is established and the overload capability makes the operation at rated power level safe and reliable. The electrical control substitutes a mechanical control, such as a turbine pitch system. Therefore, the maximum torque is an important design parameter.

The design goal was to find generators that have identical stators with the same electromagnetic characteristics. The generators should have as similar magnetic circuit as possible in the stator. The pole shoe width in the ferrite machine and the magnet width towards the airgap in the $\mathrm{NdFeB}$ machine are chosen to be the same. The air gap is the same in both generators.

The inherent difference between salient pole machines (ferrite) and non-salient pole machines $(\mathrm{NdFeB})$ means that a certain load angle at rated power for both machines will not result in the same behavior regarding voltage drop and 
maximum torque. It is therefore important to find and compare the maximum torque of the machines.

When designing the ferrite machine, focus has been placed on the electromagnetic design. However, the mechanical design is also considered. The ferrite magnets and the pole shoes are expected to be strong enough for the proposed design.

\section{RESULTS}

\section{A. Generator Characteristics}

The rotor of the $\mathrm{NdFeB}$ generator (called G1) is equipped with large, surface-mounted, high-energy NdFeB magnets. The PMs are mounted on a circular iron ring. The rotor of the ferrite generator (called G2) has magnets buried between pole shoes in order to reinforce the airgap flux. Tangentially magnetized magnets are placed between pole shoes with every other magnet magnetized in the opposite direction, i.e. two north poles will face each other forcing the flux to travel through the pole shoe to the stator. The minimum distance between two magnets is set to $15 \mathrm{~mm}$ for mounting issues. The pole shoes are made of solid iron. There is no need to laminate the poles since the electrical frequency is low. Pole shoes and magnets are mounted on a solid ring made of nonmagnetic aluminum, in order to force the flux to travel through the stator. The aluminum ring is then mounted on a steel ring connected to the shaft. The ferrite rotor has much more material than the $\mathrm{NdFeB}$ rotor, both more magnets and other parts such as pole shoes and the aluminum ring. However, the $\mathrm{NdFeB}$ rotor needs to have a supporting structure for structural integrity and for both generators the iron/steel ring needs to be connected to the shaft. The geometry of the two rotors can be seen in Fig. 2.

The stator consists of steel laminations and stator winding of PVC insulated circular cables. The circular cable shape gives an evenly distributed electric field and hence makes better use of the insulation material [18]. In large machines, a cable wound generator is of great interest since it enables the use of higher operating voltage than for traditionally wound machines [18]. A generator with high rated voltage and consequently a low rated load angle has a high maximum torque [19]. The generators are rated at $225 \mathrm{~kW}$. The generator power rating is given in $\mathrm{kW}$ rather than the more conventional $\mathrm{kVA}$, since the generator will be rectified through diodes. The generator characteristics are presented in Table II and III, where L-L voltage means line to line voltage.

The properties in Table II are exactly the same apart from load angle, cogging and airgap force. The relationship between stator iron losses and stator copper losses is the same for the two machines, which is important for the two generators to have the same efficiency characteristics at variable speed operation [20].

The maximum torque of $\mathrm{G} 1$ is $200 \mathrm{kNm}$, which is more than three times the rated torque. The maximum torque for G2 is $178 \mathrm{kNm}$, which is $11 \%$ lower, but still sufficiently large. The voltage drop at rated load is below $4 \%$ for both machines.

TABLE II

GENERATOR ELECTROMAGNETIC CHARACTERISTICS FOR RATED SPEED AND POWER FROM STATIONARY SIMULATIONS.

\begin{tabular}{lll} 
Characteristic & $G 1$ & $G 2$ \\
Active power $(\mathrm{kW})$ & 225 & 225 \\
Load L-L voltage $(\mathrm{V}) \mathrm{rms}$ & 793 & 793 \\
Current $(\mathrm{A}) \mathrm{rms}$ & 164 & 164 \\
Electrical frequency $(\mathrm{Hz})$ & 9.9 & 9.9 \\
Rotational speed $(\mathrm{r} / \mathrm{min})$ & 33 & 33 \\
Torque $(\mathrm{kNm})$ & 65 & 65 \\
Cogging $(\%$ of rated torque) & 1.8 & 1.3 \\
Electrical efficiency $(\%)$ & 96.6 & 96.6 \\
Stator copper losses $(\mathrm{kW})$ & 5.4 & 5.4 \\
Stator iron losses $(\mathrm{kW})$ & 2.4 & 2.4 \\
Load angle $\left({ }^{\circ}\right)$ & 9.6 & 9.3 \\
Airgap force $\left(\mathrm{MN} / \mathrm{m}^{2}\right)$ & 0.18 & 0.20 \\
\hline
\end{tabular}

TABLE III

ROTOR GEOMETRIC CHARACTERISTICS FORM STATIONARY SIMULATIONS. Characteristic

Number of poles

Magnet dimensions (mm)

Pole width (mm)

Al ring height $(\mathrm{mm})$

Iron ring height $(\mathrm{mm})$

Stator length $(\mathrm{mm})$

PM weight (kg)

Total rotor weight, active ${ }^{\mathrm{a}}(\mathrm{t})$

Total rotor weight $(\mathrm{t})$

Total generator weight, active ${ }^{\mathrm{a}}(\mathrm{t})$

Total generator weight $(\mathrm{t})$

\begin{tabular}{ll}
$G 1$ & $G 2$ \\
36 & 36 \\
$19 * 120 * 848$ & $100 * 350 * 809$ \\
120 & 120 \\
- & 100 \\
25 & 25 \\
848 & 848 \\
536 & 4789 \\
1.7 & 8.5 \\
3.3 & approx. 10.8 \\
6.5 & 13.3 \\
13 & 20.5 \\
\hline
\end{tabular}
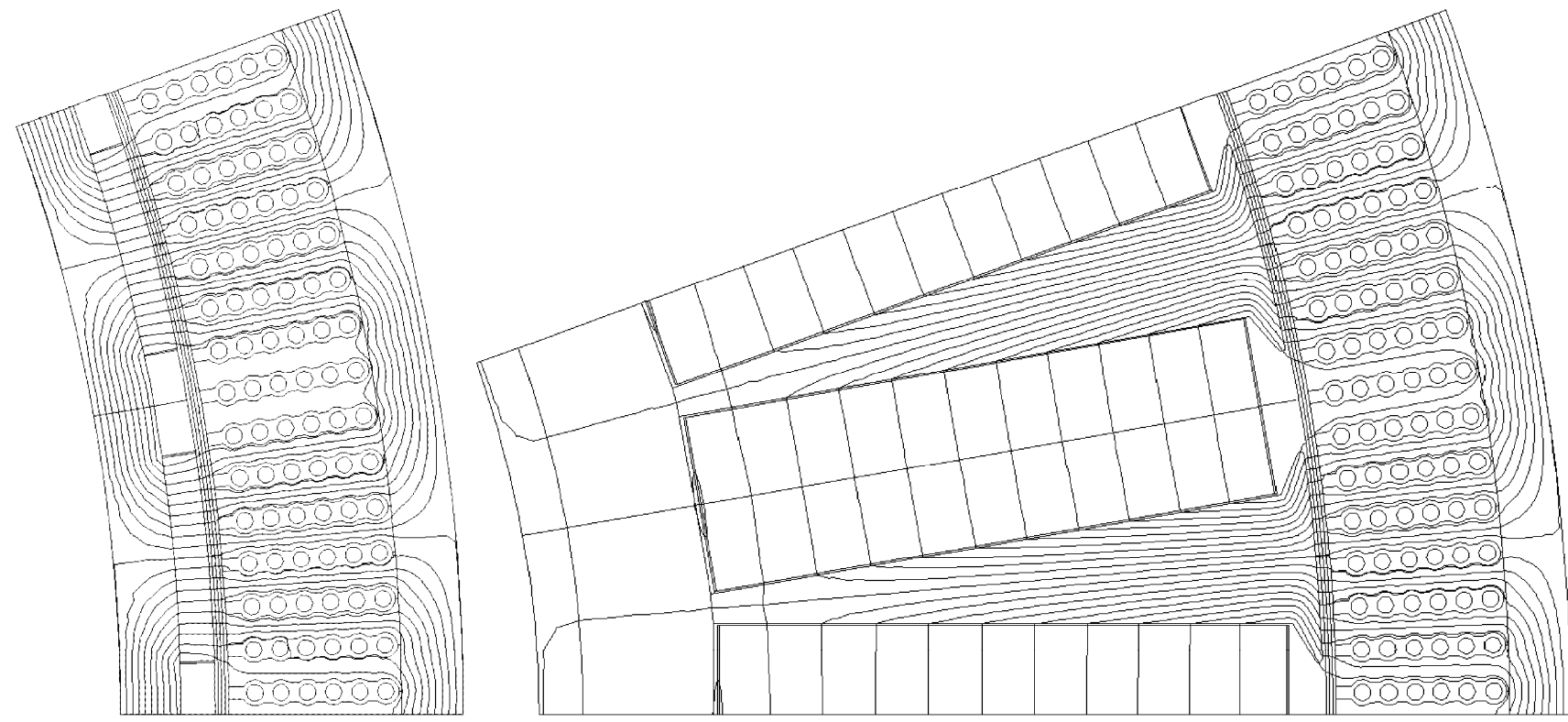

Fig 2. The two generator geometries and magnetic field lines at no load. The NdFeB generator to the left and the ferrite generator to the right. 
The results from Table II show that the goal of designing similar generators was achieved. However, the geometry in Fig. 2 as well as the results in Table III shows significant differences in geometry and weight. This is due to the difference between $\mathrm{NdFeB}$ and ferrite in remanence, permeability and mass density.

In order to achieve a generator design with as similar properties as possible concerning overload capability, load angle and voltage level, the rotor of G2 will be slightly shorter than for G1 at $809 \mathrm{~mm}$ compared to $848 \mathrm{~mm}$. The same stator of $848 \mathrm{~mm}$ will still be used.

\section{B. Generator Comparison}

The electromagnetic properties was shown in section $V . A$. to be the same or similar for the two different rotors having the same stator. However, the rotor geometry and mechanical design is different, see Table IV. The ferrite rotor weighs 3.3 times more than the $\mathrm{NdFeB}$ rotor. The ferrite magnets weigh 8.6 times more than the $\mathrm{NdFeB}$ magnets.

TABLE IV

COMPARISON OF THE TWO GENERATORS WITH DIFFERENT PM MATERIAL FOR $225 \mathrm{KW}$ MACHINES.

\begin{tabular}{llll}
\hline Characteristic & G1 & G2 & G2 rel. G1 \\
Magnet type & NdFeB & Ferrite & \\
Power rating (kW) & 225 & 225 & 1 \\
PM weight (kg) & 536 & 4589 & 8.6 \\
Rotor weight (t) & 3.3 & 10.8 & 3.3 \\
PM weight/Total generator & 0.08 & 0.36 & 4.5 \\
weight (active) & & & \\
PM weight/Total generator & 0.04 & 0.23 & 5.8 \\
weight & & & \\
Shaft eigen freq., rel. G1 & 1 & 0.55 & 0.55 \\
PM price, Feb 2012 (EUR) & 37520 & 10392 & 0.28 \\
\hline
\end{tabular}

The active material in the rotors, i.e. material that is part of the magnetic circuit, consists of PMs and iron ring for the $\mathrm{NdFeB}$ generator and PMs and pole shoes for the ferrite generator. The aluminum ring and iron ring in the ferrite rotor are part of the passive material. Both generators will need additional supporting material as well as a shaft. The total rotor weight for G1 is known and for G2 it has been approximated.

A heavier rotor changes the torsional eigen frequency for the two mass system turbine-shaft-generator rotor. The eigen frequency for torsional vibrations will be lower for the heavier rotor so the shaft needs to be dimensioned a little more conservatively for safe operation with the ferrite rotor [21]. However, the dimensioning factor for the shaft is not only the eigen frequency, but also for instance buckling. For the interchangeable rotor idea to work, the shaft needs to be designed conservatively or alternatively two different shafts could be considered.

Another difference between the two rotor types which needs to be considered is the gravitational force that the thrust bearing will be subject to. Furthermore, the heavier rotor will affect the control system, making the speed control smoother for the larger inertia but more power will be required to start the wind turbine [22].

In order to choose which rotor is most economical to build at a certain time, the price for manufactured $\mathrm{PMs}$ of $\mathrm{NdFeB}$ at that time needs to be compared to the price for ferrite PMs, see Fig. 3. The triangle indicates the NdFeB price in July 2010 of $29 \mathrm{EUR} / \mathrm{kg}$ and the square shows the price in February 2012 of 70 EUR/kg. The price for PMs for the two machines is the same at a NdFeB PM price of $19 \mathrm{EUR} / \mathrm{kg}$. In February 2012, the price for the PMs in a ferrite rotor was $28 \%$ of the price for $\mathrm{NdFeB} \mathrm{PMs.}$

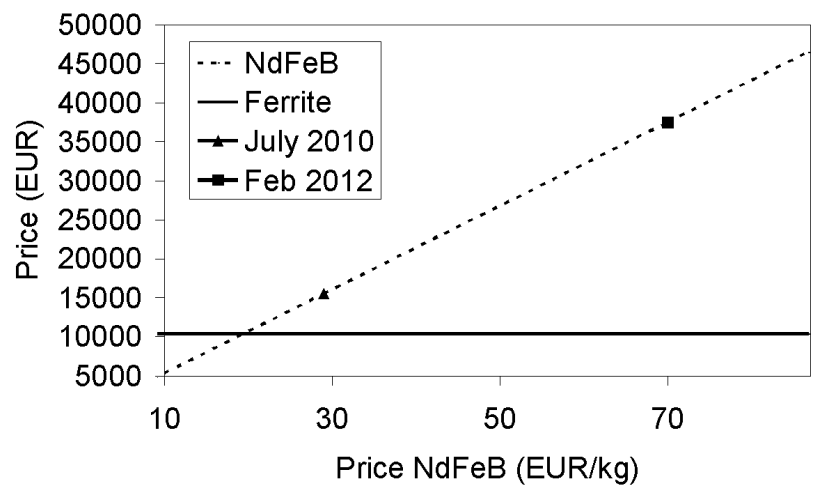

Fig 3. Price for PMs for the two $225 \mathrm{~kW}$ generators depending on the price for $\mathrm{NdFeB}$ magnets. The ferrite PM price is assumed constant at 2.17 EUR/kg. The triangle and square indicate $\mathrm{NdFeB} P M$ prices at certain times.

When deciding which generator to build other things needs to be considered as well, such as mounting issues for ferrites and pole material which would make the ferrite generator cost increase a bit. However, with the price level of February 2012, a ferrite machine should definitely be considered.

\section{DISCUSSION}

The ferrite generator design is based on the $\mathrm{NdFeB}$ generator design. The ferrite machine might have been designed differently if it didn't need to have the same properties as the $\mathrm{NdFeB}$ machine. For instance a larger outer diameter might have been chosen for the ferrite generator, to increase the minimum width of the pole shoes to more than $15 \mathrm{~mm}$. However, this would not alter the conclusions drawn from the presented analyze, since the PM weight is highly dependent on the output voltage and maximum torque. Furthermore, by having a different stator the idea with the interchangeable rotor has to be dismissed.

It could also be of interest to consider using $\mathrm{SmCo}$, which has more price stability. As the $\mathrm{Nd}$ price varies, SmCo might become an interesting alternative to $\mathrm{NdFeB}$. The $\mathrm{SmCo}$ magnets would also be surface mounted and the design would be similar to the $\mathrm{NdFeB}$ design except for slightly larger magnets (thicker) needed to achieve the same airgap flux. However, the brittleness of SmCo needs to be considered. The price for $\mathrm{SmCo}$ is not compatible with the price for ferrites.

Mounting aspects needs to be considered when deciding the generator design. It might be more difficult to mount and hold together the ferrite solution. Furthermore, the ferrite magnets are quite large and will probably need to be manufactured and mounted in segments.

The maximum torque for the ferrite machine is $11 \%$ lower than for the $\mathrm{NdFeB}$ machine. The maximum torque is roughly proportional to the PM weight, especially if geometrical constraints such as generator length, outer diameter and airgap are set, so the ferrite generator should have roughly $11 \%$ more PM weight to be comparable. However, this was difficult to achieve with the fixed geometrical constrains. The overload capability of the ferrite generator is high enough for the application.

\section{CONCLUSIONS}

The choice of PM material for PM generators is highly dependent on the political and economical price development of the magnet material. The increased demand for 
neodymium from the wind power sector is expected to stay high. The current investigation has shown that PM machines can be built with different types of material. For a vertical axis wind turbine, having the generator at ground level, the $\mathrm{NdFeB}$ and the ferrite rotor can be interchangeable. This would have a small effect of the shaft design, which could be designed to handle the heavier generator. Thereby, a vertical axis wind turbine could be sold with the, for the time being, cheapest rotor. For a horizontal axis wind turbine, on the other hand, the raw material price changes have a larger implication as a NdFeB rotor is much preferred. For conventional turbines, the generator design is highly focused on decreasing the hub weight and a weight increase will affect the rest of the structure. Thus, the possibility to have a ferrite generator is a clear cost advantage for the vertical axis wind turbine technology, especially if the $\mathrm{Nd}$ price stays high.

It has been shown that a machine with similar electromagnetic properties can be built with two different rotor designs, mainly differing in rotor weight. The choice between them depends on the magnet material price. Thereby, the generator price becomes easier to predict.

The results from Fig. 3, showing an intersection at 19 $\mathrm{EUR} / \mathrm{kg}$, can be used as a tool for designing the generator as cost efficiently as possible taking the current neodymium price into account. Results from this paper can thereby be used as a guideline for what PM material to choose.

\section{ACKNOWLEDGMENT}

Dr. A. Wolfbrandt and Doc. U. Lundin are acknowledged for assistance with electromagnetic FEM simulations. Thanks to P. Rundbom at Compotech Provider AB and T. Andersson at Sura Magnets AB for information on price development for magnetic materials.

\section{REFERENCES}

[1] C. Hurst. (2010, March). China's Rare Earth Elements Industry: What Can the West Learn?. Institute for the Analysis of Global Security (IAGS), U.S. Army's Foreign Military Studies Office, Fort Leavenworth, KS. [Online]. Available: http://www.iags.org/rareearth0310hurst.pdf

[2] J. Pyrhönen, J. Nerg, P. Kurronen, J. Puranen and M Haavisto, "Permanent magnet technology in wind power generators," Electrical Machines (ICEM), 2010 XIX International Conference on, 6-8 Sept. 2010: $1-6$.

[3] O. Danielsson,, K. Thorburn, M. Eriksson and M. Leijon, "Permanent magnet fixation concepts for linear generator", Fifth European wave energy conf., 17-19 sept, Cork, Ireland, 2003.

[4] J. Kjellin, F. Bülow, S. Eriksson, P. Deglaire, M. Leijon and H. Bernhoff, "Power Coefficient Measurement on a $12 \mathrm{~kW}$ Straight Bladed Vertical Axis Wind Turbine", Renewable Energy, 2011;36(11):3050-3053.

[5] S. Eriksson, H. Bernhoff, M. Leijon. "Evaluation of different turbine concepts for wind power". Renewable and Sustainable Energy Reviews, 2008;12(5):1419-1434.

[6] M. Dahlgren, H. Frank, M. Leijon, F. Owman, L. Walfridsson. "Windformer-wind power goes large scale". ABB Rev., 2000;3:3137.

[7] T. Miura, S. Chino, M. Takemoto, S. Ogasawara, A. Chiba and N. Hoshi, "A ferrite permanent magnet axial gap motor with segmented rotor structure for the next generation hybrid vehicle", Electrical Machines (ICEM), 2010 XIX International Conference on, 6-8 Sept. 2010: 1-6.

[8] S. Eriksson, H. Bernhoff, M. Leijon, "A 225 kW Direct Driven PM Generator Adapted to a Vertical Axis Wind Turbine", Advances in Power Electronics, vol. 2011, Article ID 239061, 7 pages, 2011.
[9] S. Eriksson, A. Solum, H. Bernhoff and M. Leijon, "Simulations and experiments on a $12 \mathrm{~kW}$ direct driven PM synchronous generator for wind power", Renewable Energy, 2008;33(4):674-681.

[10] A. Grauers, "Design of Direct Driven Permanent Magnet Generators for Wind Turbines", Ph.D. dissertation, Dept. Electric Power Eng., Chalmers University of Technology, 1996.

[11] P. Lampola, "Directly driven, low-speed permanent-magnet generators for wind power applications", Ph.D. dissertation, Dept. Electrical Eng., Helsinki University of Technology, 2000.

[12] S.A. Evans, "Novel rotor design for interior permanent magnet brushless machines: Initial investigation", Electrical Machines (ICEM), 2010 XIX International Conference on, 6-8 Sept. 2010: 1-6.

[13] S.A. Evans, "Salient pole shoe shapes of interior permanent magnet synchronous machines" Electrical Machines (ICEM), 2010 XIX International Conference on, 6-8 Sept. 2010: 1-6.

[14] F. Hetemi, G. Dajaku and D. Gerling, "Influence of magnet thickness and magnet orientation on the performance of IPMSM" Electrical Machines (ICEM), 2010 XIX International Conference on, 6-8 Sept. 2010: 1-4.

[15] J.B. Danilevich, V.N. Antipov, I.Y. Kruchinina, Y.P. Khozikov, A.A. Ponomareva and L.Y. Shtainle, "Peculiar design of permanent magnet synchronous motor", Electrical Machines (ICEM), 2010 XIX International Conference on, 6-8 Sept. 2010: 1-4.

[16] Metal prices - Neodymium. Retrieved 2012-02-06. [Online]. Available: http://www.metal-pages.com/metalprices/neodymium

[17] J. Kjellin, S. Eriksson and H. Bernhoff, "Stall regulation of a $200 \mathrm{~kW}$ vertical axis variable speed wind turbine with PM-generator", submitted to Applied Physics Letters, 2012.

[18] M. Leijon, M. Dahlgren, L. Walfridsson, L. Ming and A. Jaksts, "Windformer - A recent development in the electrical insulation systems of generators and transformers", IEEE Electrical Insulation Magazine, 2001;17(3):10-15.

[19] P. Kundur, "Power system stability and control". The EPRI Power System Engineering Series, McGraw-Hill, Inc., New York, USA, 1994:20-23.

[20] S. Eriksson and H. Bernhoff, "Loss Evaluation and Design Optimisation for Direct Driven Permanent Magnet Synchronous Generators for Wind Power", Applied Energy, 2011;88:265-271.

[21] S. Eriksson and H. Bernhoff, "Generator-Damped Torsional Vibrations of a Vertical Axis Wind Turbine", Wind Engineering, 29:5 (2005), pp.449-461.

[22] J. Kjellin, S. Eriksson, P. Deglaire, F. Bülow and H. Bernhoff, "Progress of control system and measurement techniques for a $12 \mathrm{~kW}$ vertical axis wind turbine", Proc. of European Wind Energy Conf. 2008, Brussels, Belgium.

\section{BIOGRAPHIES}

Sandra Eriksson was born 1979 in Eskilstuna, Sweden. She finished her MSc in Engineering Physics at Uppsala University, Sweden in 2003 and studied towards a $\mathrm{PhD}$ degree in engineering science with a specialization in science of electricity between 2004 and 2008. She is currently working as assistant professor at Uppsala University. Her main topic of interest is permanent magnet electrical machines.

Hans Bernhoff's research has covered a wide spectrum of disciplines in physics. He completed a PhD for Anders Flodström at KTH (Kungliga Tekniska Högskolan) in thin film technology and spectroscopy in the area of high temperature superconductors in 1992. The spectroscopy work was further pursued during a one year post-doc at IBM Research Division in Switzerland. With the interest in applied physics and engineering he turned to the area of electro technology and energy systems. In 1993, he joined ABB Corporate Research in Västerås, where he worked for eight years as a successful industrial researcher. Among other projects, the research on diamond as a wide band gap semiconductor was initiated by Hans Bernhoff as a project leader. In 2001 he joined Uppsala University to pursue research interests in wave power, pulsed power and wind power technology. At the university, groundbreaking work is performed in the area of vertical axis wind turbines and drive lines for future electrical vehicles where a new power management paradigm is explored. In May 2011 he was appointed Professor in high performance systems. Hans Bernhoff has also pursued an active career in university spin-off companies with previous CEO of Seabased $\mathrm{AB}$ a wave power spin-off. Presently he acts as a member of the board of directors at Energy Potential $\mathrm{AB}$ and he is the vice $\mathrm{CEO}$ of Vertical Wind AB. 